\title{
Development and Validation of a Novel HILIC Method for the Quantification of Low-levels of Cuprizone in Cuprizone-containing Chow
}

Fengmei Zheng ( $\square$ fengmei.zheng@biogen.com )

Biogen (United States)

Yiqing Lin

Biogen (United States)

Pierre Boulas

Biogen (United States)

\section{Research Article}

Keywords: Cuprizone, Hydrophilic interaction liquid chromatography (HILIC) HPLC, Cuprizone-based chowii, Quantification, Stability of cuprizone

Posted Date: May 5th, 2021

DOl: https://doi.org/10.21203/rs.3.rs-465817/v1

License: (c) (i) This work is licensed under a Creative Commons Attribution 4.0 International License. Read Full License 


\section{Development and validation of a novel HILIC method for the}

\section{2 quantification of low-levels of cuprizone in cuprizone-containing}

\section{3 chow}

4

5

Fengmei Zheng ${ }^{*}$, Yiqing Lin, Pierre Boulas

6 Pharmaceutical Development, Biogen, 225 Binney St., Cambridge, MA 02142, USA

*Corresponding Authors: Fengmei.zheng@Biogen.com

Abstract

Cuprizone is an amide compound that has been wildly used in various animal studies, such as in the investigation of remyelination in mouse model. It is important to control the amount of cuprizone dosed in animals to be consistent as different amounts may lead to different clinical observations. Cuprizone is usually administrated as a minor component (i.e. $0.3 \%$ ) of a mixture with powdered or pelleted rodent chow. Its low content, combined with the complex nature of chow, represents a significant challenge for the quantification of cuprizone in the mixture. To the best of our knowledge, no method has been reported in the literature so far. In this study, a simple, selective, and sensitive hydrophilic interaction liquid chromatographic method was developed for the quantification of cuprizone in cuprizone pre-clinical formulations. The analytical method comprises a fast ultrasound assisted extraction with acetonitrile/water as a solvent followed by HILIC separation using a Waters Xbridge HILIC column and UV detection. The specificity, linearity, accuracy, repeatability, and limit of quantitation (LOQ) of the method were established. This method has been demonstrated to be suitable for its intended use and has been successfully applied to the quantification of low levels of cuprizone in chow formulations. It was found that the cuprizone content in chow could varied significantly between batches and the potential causes of the variability were investigated.

\section{Keywords:}

28 Cuprizone

29 Hydrophilic interaction liquid chromatography (HILIC) HPLC

30 Cuprizone-based chow 
32 Stability of cuprizone

\section{1. INTRODUCTION}

Cuprizone (oxalic acid bis(cyclohexylidene hydrazide)) (Figure 1) is a well-known coppercheating agent(1). Cuprizone-induced toxicity has been extensively used to study experimental remyelination. In the cuprizone model, animals are fed with cuprizone to cause oligodendrocyte death and result in consistent demyelination (2-5). The experimental results showed that different amount of the cuprizone might result in different clinical observations. For example, Carlton found that mice fed with different doses of cuprizone (ranging from 0.2 to $0.5 \%$ ) mixed in basic chow showed signs of growth retardation in a dose-dependent manner (6). In addition, Carlton and Ludwin observed the high mortality in mice administered with higher concentrations $(0.5 \%)$ cuprizone in chow $(6,7)$; Zhen also found that mice from a $800 \mathrm{mg} / \mathrm{kg}$ dosing group died while mice from the $400 \mathrm{mg} / \mathrm{kg}$ dosing arm survived following 5 weeks of administrations (8). Stidworthy et al observed that $0.2 \%$ cuprizone was a more suitable dose than $0.4 \%$ in terms of mouse morbidity and weight loss (9). Therefore, carefully controlling the amount of cuprizone in the cuprizone-based chows administrated to the animals is critical to achieve the desired results.

In our research work, cuprizone-containing chow was also used for demyelination studies with mouse model. Recently we found that when animals were fed with two different batches (batch A and batch B) of cuprizone-containing chow, the animal group fed with batch A showed significant demyelination of the corpus callosum with weight loss, which was a good indicator of a working model. However, the other animal group fed with batch B did not show the same pattern of weight loss. Histology analysis on mice fed with batch B of cuprizone chow confirmed that there was no demyelination (Figures 2 and 3).

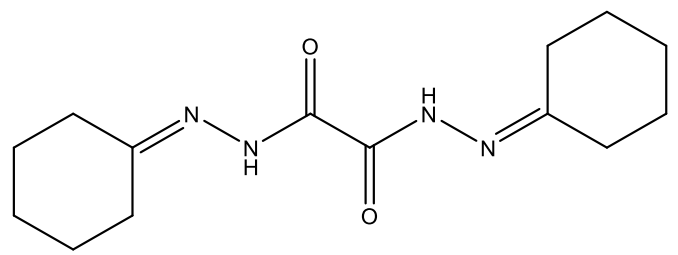

N,N'- bis(cyclohexylideneamino)ethanediamide

Figure 1. Chemical structure of cuprizone 

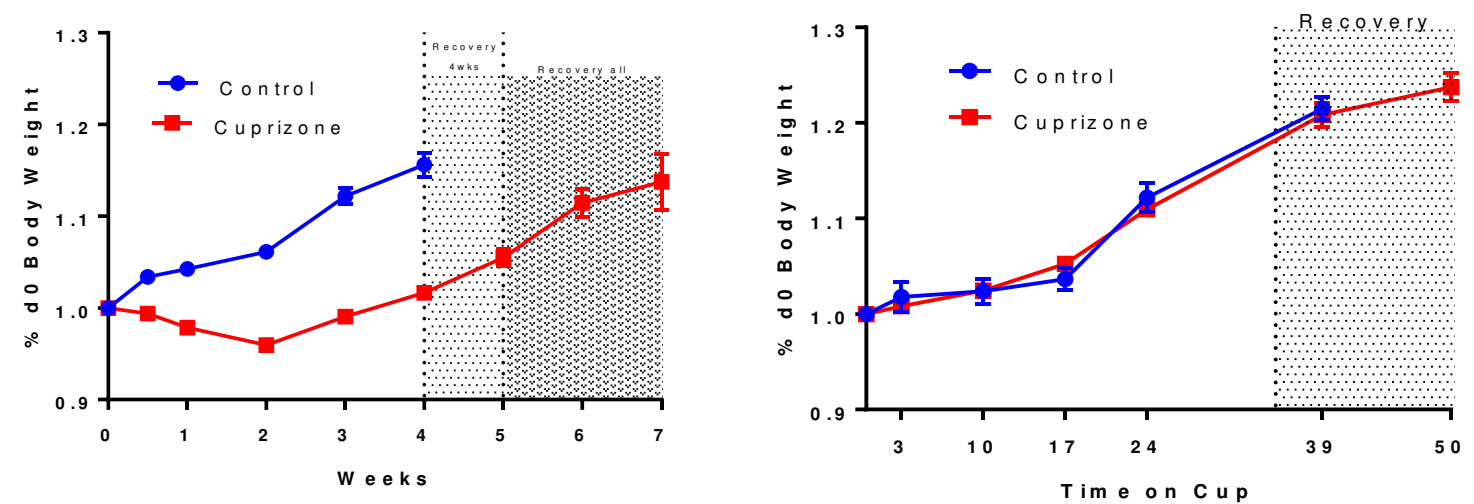

60 Figure 2. Weight loss of the mice were treated with chow placebo (control) and $0.3 \%$ cuprizonecontaining chow (batch A), $0.3 \%$ cuprizone-containing chow (batch B)
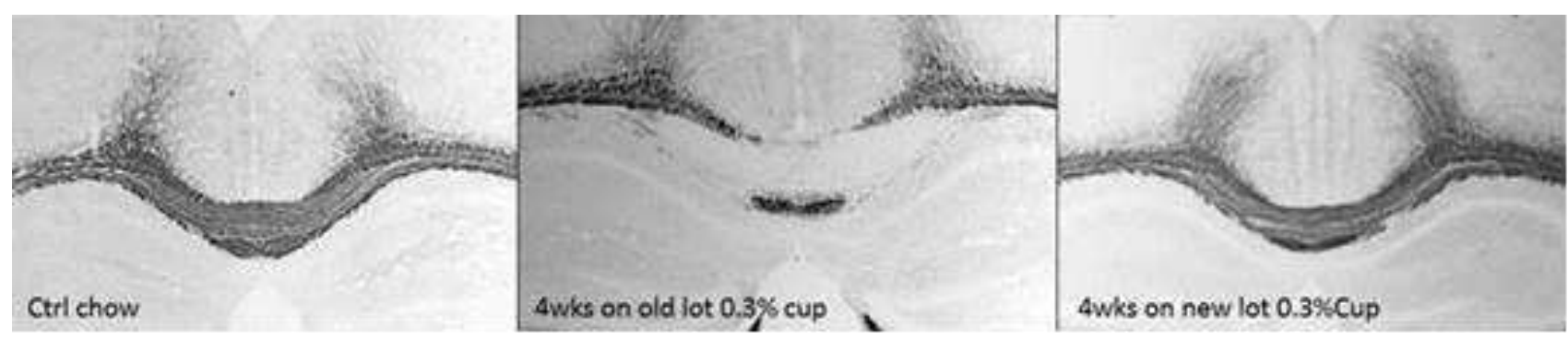

Figure 3. Demyelination detected in corpus callosum by black gold staining: The mouse on the left is on control chow, the middle mouse shows great demyelination of the corpus callosum using the batch A chow, and the mouse on the right was from the mouse using the batch B chow.

It was hypothesized that dosing of less than the target amount of cuprizone due to inhomogeneous mixing of cuprizone with chow or degradations of cuprizone during formulation preparation may account for the lack of demyelination effect observed in the study. To prove this hypothesis, a quantification method was required for the analysis of low levels of cuprizone in chow mixtures. To the best of our knowledge, no such method has been reported in the literature so far.

HPLC, with its high selectivity and accuracy, has been widely used for the quantification of analytes in complex samples. In our lab, multiple attempts to develop a reversed phase HPLC method for the analysis of cuprizone in the chow were not successful due to its coelution with the 
76 chow placebo peaks. In contrast to reversed phase HPLC, which employs a nonpolar stationary 77 phase (SP) and a polar mobile phase (MP), hydrophilic interaction liquid chromatography (HILIC) 78 uses a polar hydrophilic (normal) SP and an aqueous-polar organic solvent MP and provides a 79 different elution order and selectivity from reversed phase HPLC (10). In recent years, it has been increasingly applied to the separation and determination of polar pharmaceutical drugs and metabolites and provides a potential solution for the quantification of cuprizone in chow (10-14).

In this study, a simple, selective, and sensitive HILIC method has been developed for the determination of low levels of cuprizone in cuprizone-based chows. Separation was achieved on a HILIC column using gradient elution with $0.1 \%$ TFA in water and acetonitrile as mobile phases and UV detection at $220 \mathrm{~nm}$. The method was validated according to ICH guideline requirements and was determined to be linear in the range of $10-200 \mu \mathrm{g} / \mathrm{mL}$. Method accuracy and recovery were assessed by spiking a chow placebo with various amounts of a cuprizone reference standard to achieve concentration levels of 10,120 and $200 \mu \mathrm{g} / \mathrm{mL}$ (triplicate preparations). Method repeatability was demonstrated at the concentration of $100 \mu \mathrm{g} / \mathrm{mL}$. The method was found to be specific with a quantitation limit of $2.5 \mu \mathrm{g} / \mathrm{mL}$.

\section{MATERIALS AND METHODS}

\section{2.1. Materials}

93 Cuprizone was purchased from Sigma. HPLC grade Acetonitrile (MeCN), water, trifluoracetic acid (TFA) were purchased from Fisher Chemical (reagents are considered equivalent if

performance as specified in system suitability is met). Cuprizone placebo sample (Global $16 \%$ Protein Chow) and Cuprizone Chow samples (0.3\%wt of Cuprizone in protein chow) were provided by research group in Biogen.

\subsection{Instrumentation}

Agilent HPLC system (or equivalent instrument) equipped with UV-vis absorbance detector and Empower 3 software was employed for analyses. The analytical conditions were listed below (Table 1)

\section{Table 1}

103 Analytical Conditions

Instrument: $\quad$ Agilent 1200 HPLC 


\begin{tabular}{|c|c|c|c|c|}
\hline Detector: & \multicolumn{4}{|c|}{ UV $220 \mathrm{~nm}$, bandwidth $4 \mathrm{~nm}$, Reference off } \\
\hline Software: & \multicolumn{4}{|c|}{ Empower 3} \\
\hline (MPA) Mobile Phase A: & \multicolumn{4}{|c|}{$0.1 \%$ TFA in water } \\
\hline (MPB) Mobile Phase B: & \multicolumn{4}{|c|}{ Acetonitrile $(\mathrm{MeCN})$} \\
\hline Diluent: & \multicolumn{4}{|c|}{ 50:50 (v/v) Acetonitrile: water } \\
\hline reference Solution: & \multicolumn{4}{|c|}{ Cuprizone in Diluent } \\
\hline $\begin{array}{r}\text { Matrix reference } \\
\text { Solution/control solution: }\end{array}$ & \multicolumn{4}{|c|}{ Cuprizone in placebo Chow blank } \\
\hline Column: & \multicolumn{4}{|c|}{ Waters Xbridge HILIC, $5 \mu \mathrm{m} 4.6 \times 250 \mathrm{~mm}$} \\
\hline Column Temperature: & \multicolumn{4}{|c|}{$25^{\circ} \mathrm{C}$} \\
\hline Autosampler Temperature: & \multicolumn{4}{|c|}{ Ambient } \\
\hline Injection Volume: & \multicolumn{4}{|c|}{$10 \mu \mathrm{L}$} \\
\hline Flow Rate: & \multicolumn{4}{|c|}{$0.8 \mathrm{~mL} / \mathrm{min}$} \\
\hline Retention Time: & \multicolumn{4}{|c|}{$\sim 6.6$ minutes } \\
\hline Injections / Sample: & \multicolumn{4}{|l|}{1} \\
\hline Run Time: & \multicolumn{4}{|c|}{14 minutes } \\
\hline Calibration Curve: & \multicolumn{4}{|c|}{$\mathrm{y}=\mathrm{Ax}+\mathrm{B}$ (not weighted) } \\
\hline Elution mode: & \multicolumn{4}{|c|}{ Gradient (see below) } \\
\hline Time (mins) & 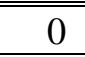 & 12 & 13 & 14 \\
\hline$\%$ MPA & 5 & 50 & 5 & 5 \\
\hline$\% \mathrm{MPB}$ & 95 & 50 & 95 & 95 \\
\hline
\end{tabular}

\subsection{Standard Solution Preparation}

A stock solution (SS) of $800 \mu \mathrm{g} / \mathrm{mL}$ was prepared by dissolving $16 \mathrm{mg}$ of cuprizone in $50 \mathrm{~mL}$ of 1:1 MeCN: water as the sample solvent. The working standards were prepared through a sequential

Table 2

111 Preparation of the working Standard Solutions

\begin{tabular}{||c|c|c|c||}
\hline Standard ID & $\begin{array}{c}\text { SS } \\
(\mathrm{mL})\end{array}$ & $\begin{array}{c}\text { Final Volume with } \\
\text { Diluent }(\mathrm{mL})\end{array}$ & $\begin{array}{c}\text { Final Concentration } \\
(\mu \mathrm{g} / \mathrm{mL})\end{array}$ \\
\hline \hline S-1 & 2.5 & 10 & 200 \\
\hline S-2 & 1.25 & 10 & 100 \\
\hline S-3 & 0.75 & 10 & 60 \\
\hline S-4 & 0.5 & 10 & 40 \\
\hline S-5 & 2.5 ml of S-6 & 10 & 10 \\
\hline
\end{tabular}

112

113 A QC stock solution (QCS) of $200 \mu \mathrm{g} / \mathrm{mL}$ was prepared by dissolving $10 \mathrm{mg}$ of cuprizone in 50

$114 \mathrm{~mL}$ of the placebo blank diluent. The placebo blank diluent was prepared by adding $\sim 4 \mathrm{~g}$ of chow 115 placebo into $100 \mathrm{~mL} \mathrm{1:1} \mathrm{MeCN}$ : water, followed by vortexing and sonication for 5 minutes, and 116 filtration with $0.45 \mu \mathrm{m}$ membrane filter. The collected filtrate was used as a diluent for preparing the 
117 matrix reference standards. The QC samples of 10, 120 and $200 \mu \mathrm{g} / \mathrm{mL}$ were prepared in triplicate

118 by diluting the QC stock solution sequentially with the placebo blank diluent according to Table 3.

Table 3.

121 Preparation of QC Samples

\begin{tabular}{||c|c|c|c||}
\hline \hline Sample ID & $\begin{array}{c}\text { QCS } \\
\text { Volume } \\
(\mathrm{mL})\end{array}$ & $\begin{array}{c}\text { Final Volume with } \\
\text { placebo diluent }(\mathrm{mL})\end{array}$ & $\begin{array}{c}\text { Final TA } \\
\text { Concentration }(\mu \mathrm{g} / \mathrm{mL})\end{array}$ \\
\hline \hline QC-1 & 10.0 & 10 & 200 \\
\hline QC-2 & 6.0 & 10 & 120 \\
\hline QC-3 & 0.5 & 10 & 10 \\
\hline
\end{tabular}

122

\section{4. Sample preparation for HPLC analysis}

Cuprizone chow and placebo chow samples were provided by our research group. For each sample, after grinding, around $2 \mathrm{~g}$ of fine powder was accurately weighed and transferred into a 50 $\mathrm{mL}$ of volumetric flask. About $40 \mathrm{~mL}$ of sample solvent then was added to the flask. To increase extraction efficiency, the sample was ultra-sonicated for 5 min and then QS with the sample solvent to $50 \mathrm{ml} .5 \mathrm{~mL}$ of the resulting suspensions was then filtrated through a $0.45 \mu \mathrm{m}$ membrane filter. The first $3.0 \mathrm{~mL}$ of the filtrate were discarded, and the rest of the filtrate was collected for HPLC analysis.

\subsection{Method validation}

The method was validated in accordance with ICH Q2(R1) for specificity, linearity and range, repeatability, and accuracy.

\section{RESULTS AND DISCUSSION}

\subsection{HILIC method development and optimization}

Cuprizone contains both hydrophobic and hydrophilic functional groups and thus could 138 theoretically be analyzed by either RP-HPLC or HILIC-HPLC. Both methods were explored to

139 achieve the retention of cuprizone on column and the separation of cuprizone from the chow placebo 140 interference peaks. Multiple RP-HPLC columns were screened and in all the cases cuprizone was 141 observed to either elute with the solvent front or coelute with the chow placebo peaks, such as shown 142 in Figure 4. In comparison, cuprizone was separated from the chow placebo peaks when using a 
143 Waters Xbridge HILIC column. Using this column, mobile phase and sample diluent were then 144 optimized.

145

146

147

148

149

150

151

152

153

154

155

156

157

158

159
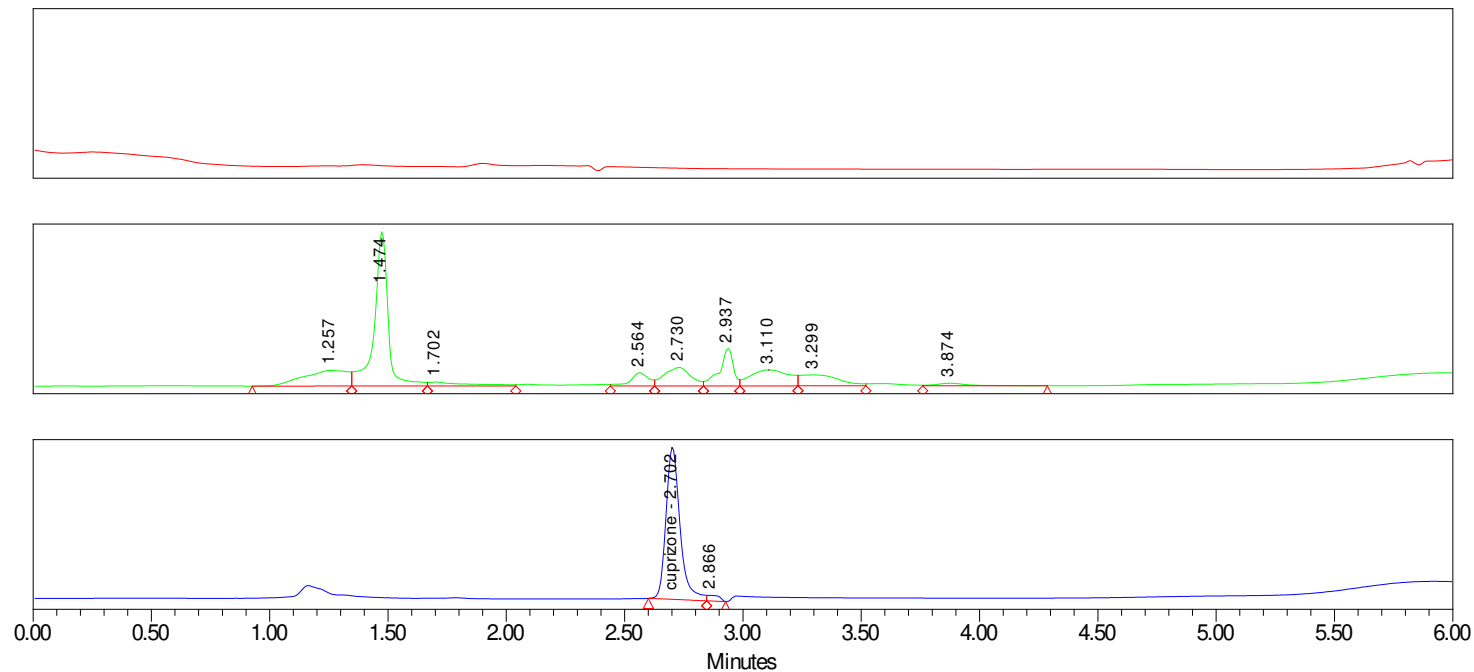

Figure 4. HPLC chromatograms of Cuprizone samples separated with Altantis T3 column; top) sample solvent (1:1 MeCN: water); middle) Chow placebo blank; bottom) $100 \mu \mathrm{g} / \mathrm{mL}$ cuprizone reference standard

\subsubsection{Column Selection}

Table 4 summarized the experimental results from screening of multiple RP and HILIC columns to achieve the separation of cuprizone from the chow placebo interference peaks. The results indicated that none of the three RP columns were suitable as retention of cuprizone on the column or separation of cuprizone from the interference peaks was not achievable. Of the two HILIC columns screened, the Waters Xbridge HILIC column $(5 \mu \mathrm{m}, 4.6 \times 250 \mathrm{~mm})$ showed promising results and therefore was selected for further investigation.

\section{Table 4.}

Summary of the columns screened for the method development

\begin{tabular}{|l|l|l|}
\hline Column tested & $\begin{array}{l}\text { Column } \\
\text { type }\end{array}$ & results \\
\hline Agilent Eclipse XDB-C18 & RP & Cuprizone elute with solvent front \\
\hline Phenomenex Kinetex-C18 & RP & Cuprizone elute with solvent front \\
\hline Atlantis T3 & RP & Cuprizone co-eluted with chow placebo peaks \\
\hline
\end{tabular}




\begin{tabular}{|l|l|l|}
\hline Atlantis HILIC Silica & HILIC & Cuprizone co-eluted with chow placebo peaks \\
\hline Waters Xbridge HILIC, $5 \mu \mathrm{m}$ & HILIC & Cuprizone retention on column and separation from \\
$4.6 \times 250 \mathrm{~mm}$ & & \begin{tabular}{l} 
interference peaks achieved \\
\hline
\end{tabular}
\end{tabular}

\subsubsection{Effect of sample solvent}

162 It was found that sample solvent had an impact on the cuprizone peak shape. As indicated in

163 Figure 5, when 1:1 mixture of $\mathrm{MeOH} /$ water was used as the sample solvent, peak splitting was observed. In contrast, decent peak shape was achieved when using 1:1 mixture of MeCN/water as the sample solvent. The observed distortion of peak shape may arise from mismatch of sample solvent and mobile phase, which is one of the most common challenges in HILIC. Compared to 1:1 $\mathrm{MeCN} /$ water, 1:1 MeOH/water has higher elution strength in HILIC, which impairs the partitioning of the analytes into the stationary phase and results in peak distortion.
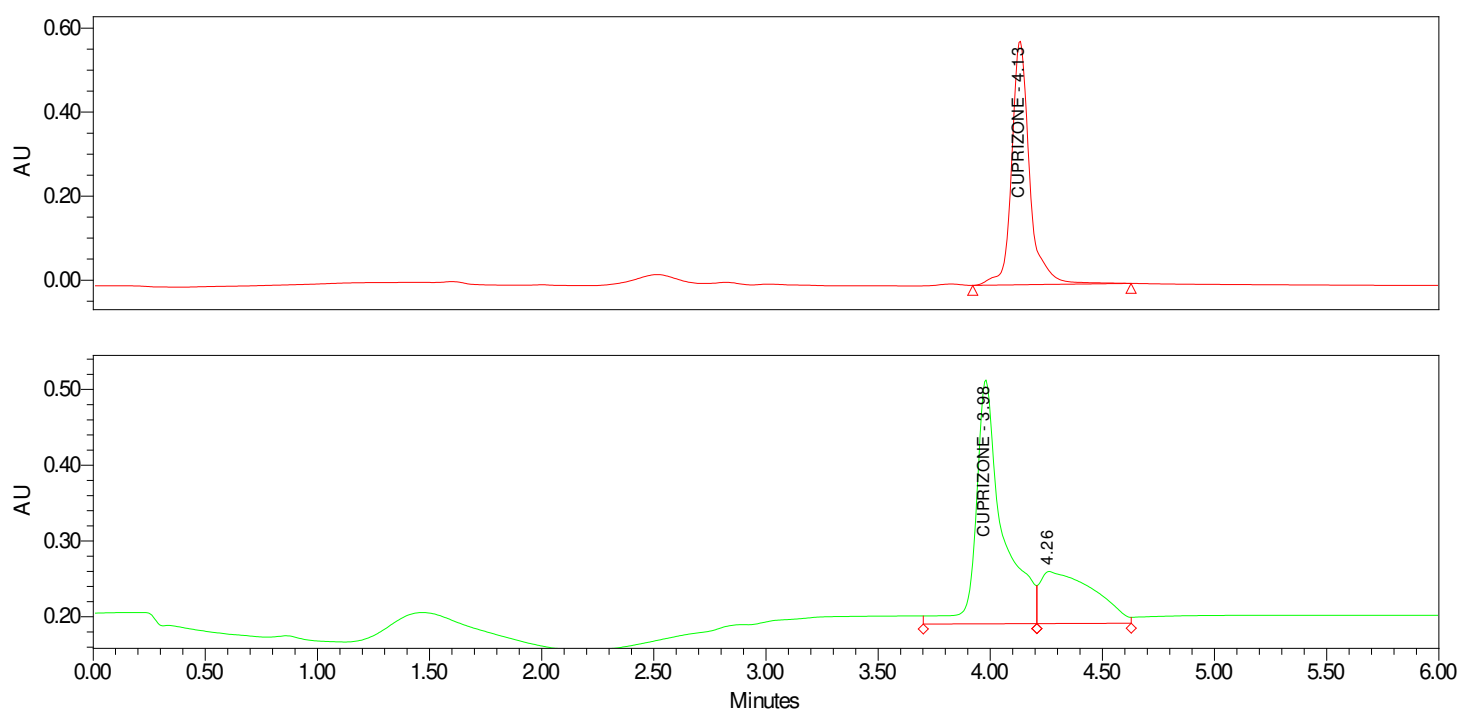

171 Figure 5. HPLC chromatograms for cuprizone reference standards, Xbridge HILIC column, top) 1:1

$172 \mathrm{MeCN}$ : water as sample solvent; bottom) 1:1 MeOH: water as sample solvent

\section{3.1.3. Effect of mobile phase}

175 Mobile-phase $\mathrm{pH}$ and buffer ions play an important role in HILIC retention since they can 176 influence the electric charge state of both ionizable solutes and stationary phase, which may affect 177 the thickness of the stagnant enriched aqueous layer on the surface of the stationary phase. This is 
178 turn can lead to an additional ionic interaction which can impact the solutes retention. To examine 179 this effect (analyte retention and peak shape), three mobile phases: water/MeCN, $0.1 \% \mathrm{TFA}$ in 180 water/MeCN and $25 \mathrm{mM}$ phosphate buffer/MeCN were investigated (Figure 6). The results 181 indicated that $\mathrm{pH}$ and ion strength did not significantly affect the retention of cuprizone on the 182 Waters Xbridge HILIC column. $0.1 \%$ TFA in water/MeCN was eventually selected as the mobile 183 phases for better peak retention and peak shape.

184
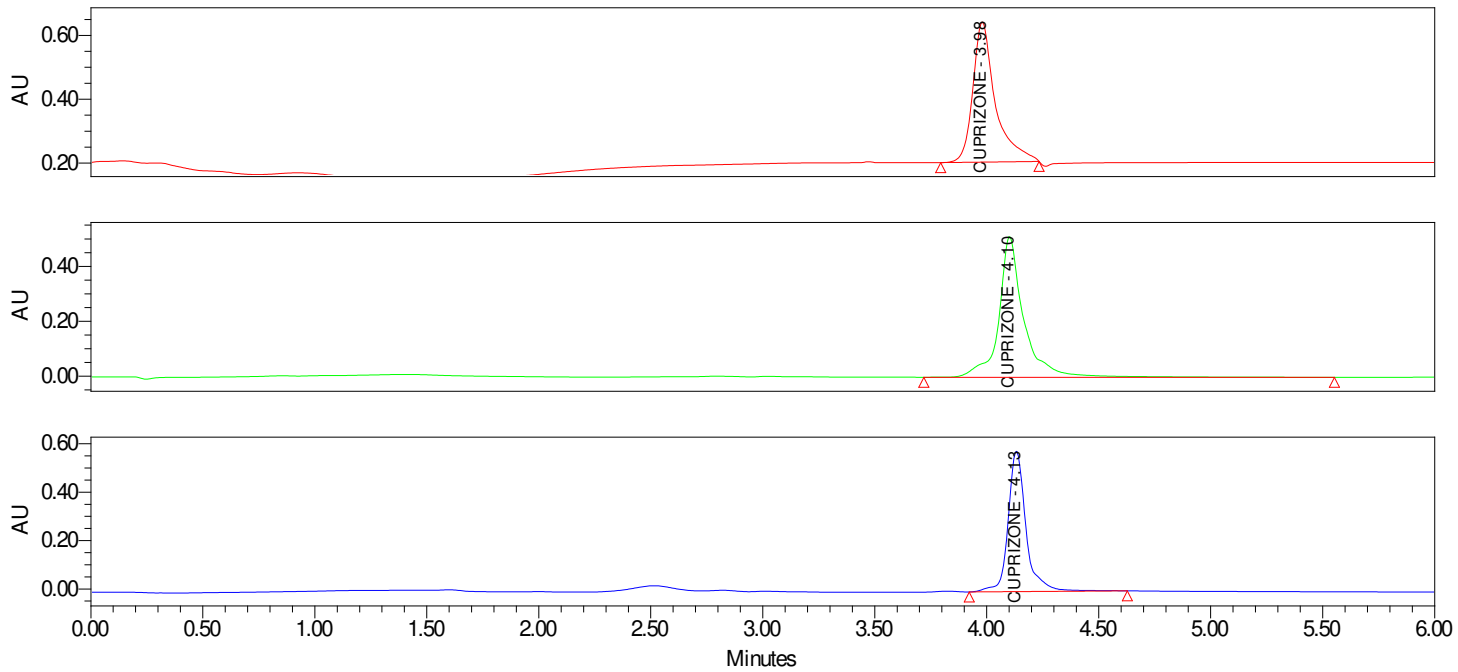

185

186 Figure 6. HPLC chromatogram of Cuprizone in Xbridge HILIC column with different mobile phases

187 (from top to bottom): water/ $\mathrm{MeCN} ; 25 \mathrm{mM}$ phosphate in water/ MeCN and 0.1\%TFA in water/ $188 \mathrm{MeCN}$

189 Through optimization, the analytical method conditions listed in table 1 were developed for 190 further validation. Representative chromatograms are shown in Figure 7.

191

192

193 

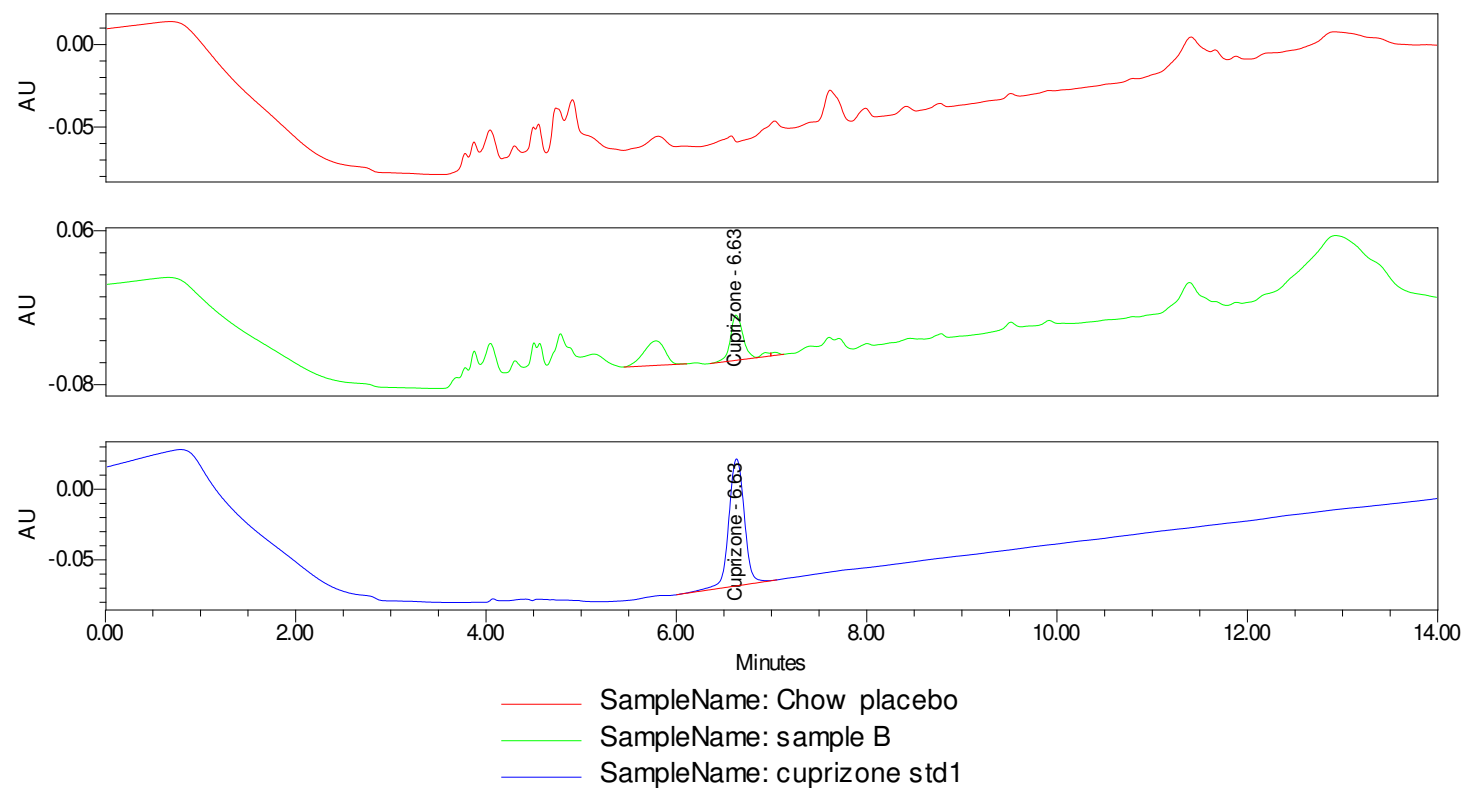

194

SampleName: sample B

195 Figure 7. HPLC chromatogram of Cuprizone samples in Xbridge HILIC column, from top to 196 bottom: Chow placebo blank, cuprizone-based chow sample and $100 \mu \mathrm{g} / \mathrm{mL}$ cuprizone reference 197 standard.

198

199

\subsection{Method validation}

200 The calibration curve for cuprizone was obtained using a series of standard solutions over the 201 concentration range of $10-200 \mu \mathrm{g} / \mathrm{ml}$. A linear relationship between the peak area of the cuprizone 202 and the concentration of the standard with $\mathrm{R}^{2}=0.9998$ was obtained (Table 5, Figure 8). The 203 percent recovery for each standard prepared met the acceptance criterion of $90-110 \%$ of the nominal 204 concentration. The correlation coefficient of the calibration curve met the acceptance criterion of $\mathrm{R}^{2}$ $205 \geq 0.99$. 
Table 5.

207 Results of Solvent Standards for Validation

\begin{tabular}{|c|c|c|c|c|}
\hline $\begin{array}{c}\text { Solvent } \\
\text { Standard ID }\end{array}$ & $\begin{array}{c}\text { TA Conc. } \\
(\mu \mathrm{g} / \mathrm{mL})\end{array}$ & $\begin{array}{c}\text { TA } \\
\text { Peak Area }\end{array}$ & $\begin{array}{c}\text { Calc. Conc. } \\
(\mu \mathrm{g} / \mathrm{mL})\end{array}$ & $\begin{array}{c}\% \\
\text { Recovery }\end{array}$ \\
\hline S-0 (solvent blank) & 0 & NA & NA & NA \\
\hline S-5 & 10 & 146507 & 10.8 & 107.9 \\
\hline S-4 & 40 & 566680 & 41.7 & 104.4 \\
\hline S-3 & 60 & 851289 & 62.7 & 104.5 \\
\hline S-2 & 100 & 1369820 & 100.0 & 100.0 \\
\hline S-1 & 200 & 2784301 & 205.1 & 102.5 \\
\hline \multicolumn{3}{|c|}{ Correlation Coefficient } & \multicolumn{2}{c|}{0.9998} \\
\hline \multicolumn{2}{|c|}{ Slope } & 8553.2 \\
\hline
\end{tabular}

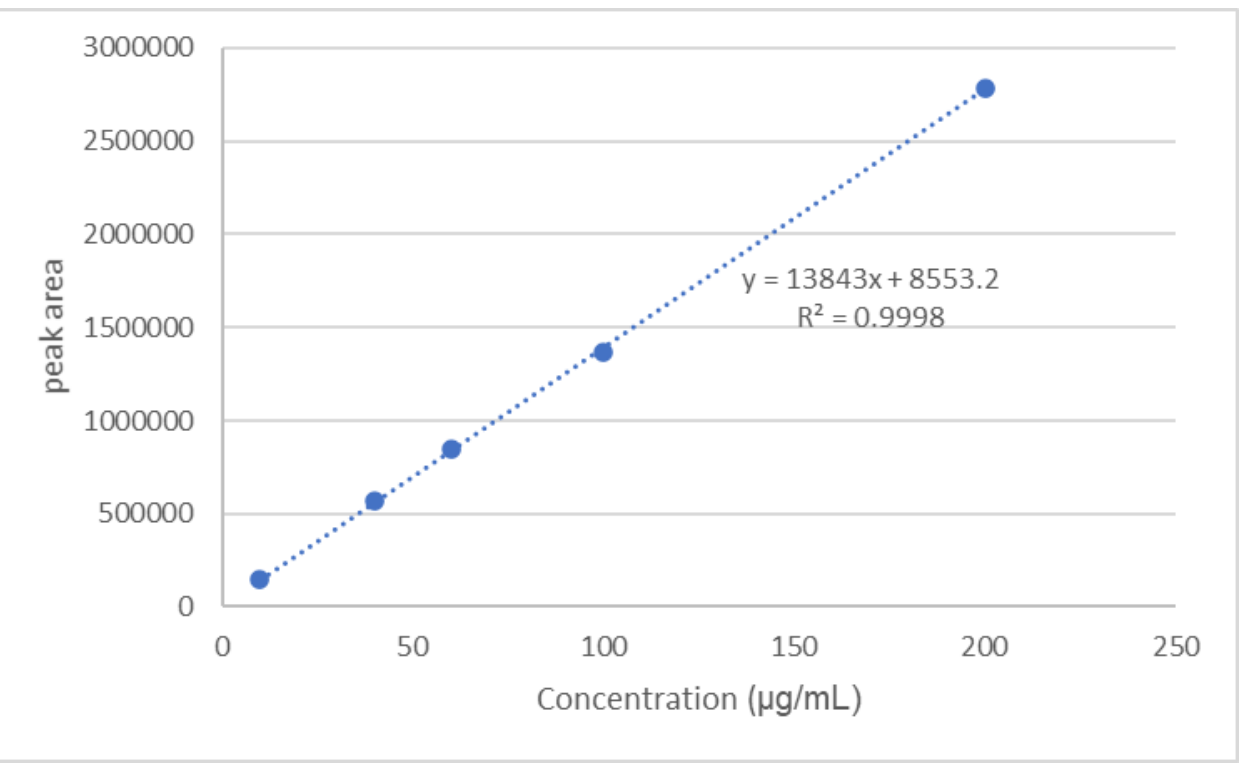

Figure 8. Calibration curve for cuprizone solutions

211 The analytical accuracy and recovery of the method was assessed using 9 determinations over 3

212 concentration levels (3 replicates/concentration level) covering the specified range of $10-200$

$213 \mu \mathrm{g} / \mathrm{ml}$. The QC samples were prepared by adding reference standard to the placebo blank matrix.

214 The method was shown to be accurate at concentration levels of 10,120 and $200 \mu \mathrm{g} / \mathrm{mL}$ with 215 RSD values (triplicate preparations) of $0.51 \%, 0.28 \%$ and $0.72 \%$ for cuprizone, respectively. The 216 percent recovery for each standard prepared met the acceptance criterion of 90-110\% of the nominal 217 concentration.

218 Table 6

219 Accuracy and of recovery of the cuprizone method 


\begin{tabular}{||c|c|c|c|c||}
\hline $\begin{array}{c}\text { Sample } \\
\text { Solution ID }\end{array}$ & $\begin{array}{c}\text { Concentration } \\
(\mu \mathrm{g} / \mathrm{mL})\end{array}$ & $\begin{array}{c}\text { recovery } \\
\text { Concentration } \\
(\mu \mathrm{g} / \mathrm{mL})\end{array}$ & Recovery $(\%)$ & RSD (n=3) \\
\hline \hline QC-1 & 200 & 198.5 & 99.3 & 0.72 \\
\hline QC-2 & 120 & 112.5 & 93.7 & 0.28 \\
\hline QC-3 & 10 & 10.5 & 104.9 & 0.51 \\
\hline
\end{tabular}

220

221 The repeatability of the method was determined by six injections of the $100 \mu \mathrm{g} / \mathrm{mL}$ standard at 222 the beginning of the analysis. Cuprizone peak area and Cuprizone retention time were evaluated. 223 All acceptance criteria were met. The results are shown in Table 7.

Table 7

226 The repeatability for the Method Validation $(100 \mu \mathrm{g} / \mathrm{mL}$ reference standard)

\begin{tabular}{|c|c|c|}
\hline \hline & $\begin{array}{l}\text { Cuprizone } \\
\text { Peak Area }\end{array}$ & $\begin{array}{c}\text { Cuprizone Retention Time } \\
\text { (Minutes) }\end{array}$ \\
\hline Injection 1 & 1369820 & 6.64 \\
\hline Injection 2 & 1373874 & 6.62 \\
\hline Injection 3 & 1373711 & 6.62 \\
\hline Injection 4 & 1372307 & 6.62 \\
\hline Injection 5 & 1373168 & 6.62 \\
\hline Injection 6 & 1365070 & 6.60 \\
\hline \hline Average & 1372576 & 6.62 \\
\hline \hline \% RSD & 0.12 & 0.14 \\
\hline Acceptance Criterion $\leq \%$ RSD & 2 & 5 \\
\hline
\end{tabular}

The limit of quantification (LOQ) was $2.5 \mu \mathrm{g} / \mathrm{mL}$, determined as the concentration of cuprizone that gives rise to peak height with a $\mathrm{S} / \mathrm{N} \geq 10$. (Figure 9) 


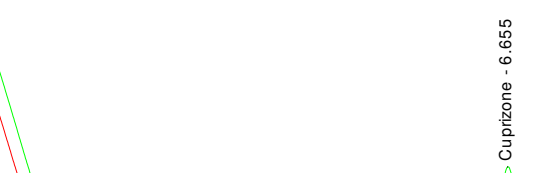

231 Figure 9. Chromatogram of LOQ reference standard (2.5 $\mu \mathrm{g} / \mathrm{mL}$, top) and sample solvent (1:1 232 MeCN: water, bottom)

233 System stability/reproducibility of the standards on the autosampler for the duration of the 234 analytical run was evaluated by comparison of the average of the six system suitability injections at 235 the beginning of the analysis with the injection of $100 \mu \mathrm{g} / \mathrm{mL}$ at the end of the analysis. The peak 236 areas obtained met the acceptance criterion of $<5 \%$ change over the course of the analysis (Table 8$)$.

238 Table 8

239 Autosampler Stability for Validation

\begin{tabular}{|c|c|c||}
\hline & $\begin{array}{c}\text { Cuprizone } \\
\text { Peak Area }\end{array}$ & $\begin{array}{c}\% \\
\text { Difference }\end{array}$ \\
\hline \hline System Suitability (Average) & 1372576 & $+0.09 \%$ \\
\hline End of Analysis & 1373874 & \\
\hline
\end{tabular}

All acceptance criteria were met and the analytical method for the determination of Cuprizone in Cuprizone containing chow was validated.

\subsection{Batch analysis of cuprizone-containing chow}

The HILIC-HPLC method was applied to the determination of cuprizone content in the two 246 to batch A with a cuprizone content of $0.32 \%$, batch B had a much lower cuprizone content of $2470.08 \%$. This explains why demyelination and weight loss were not observed in the animal group fed 248 with batch B. 
Table 9

250 Cuprizone amount in the cuprizone-containing chow batches

\begin{tabular}{||c|c|c|c||}
\hline Sample information & Label claim & $\begin{array}{c}\text { \% cuprizone detected with the } \\
\text { HILIC HPLC method }\end{array}$ & \% label claim \\
\hline \hline $0.3 \%$ cuprizone chow (batch A) & $0.3 \%$ & $0.32 \%$ & $107 \%$ \\
\hline $0.3 \%$ cuprizone chow (batch B) & $0.3 \%$ & $0.08 \%$ & $27 \%$ \\
\hline
\end{tabular}

251

\subsection{Investigation of batch-to-batch variability of cuprizone content in chow formulation}

Cuprizone-containing chow is typically made by mixing cuprizone and chow together with the addition of water at the end of the mixing to generate pellets followed by drying the pellets at $50{ }^{\circ} \mathrm{C}$ under vacuum for a few hours. Three potential causes, independently or together, could account for the low cuprizone content in cuprizone-containing chow batch B: 1) inhomogeneous mixing of cuprizone with chow; 2) degradation of cuprizone during mixing and/or drying; 3) degradation of cuprizone during storage of chow before use. Since it was difficult to know if inhomogeneous mixing was a cause for the low chow content and the chow formulation was demonstrated to be stable under typical storage conditions, we focused our studies on exploring the potential degradation of cuprizone during mixing and/or drying.

To determine if the water amount and/or the drying conditions have any impact on the degradation of cuprizone, samples were prepared by mixing cuprizone with the chow placebo and adding different amount of water to the mixture. The samples were then stored at ambient temperature or dried at $50^{\circ} \mathrm{C}$ in a vacuum oven for different duration. After drying, the samples were analyzed using the developed HILIC-HPLC method. The experimental design and results were summarized in Table 10.

Table 10

270 Stability of Cuprizone in different conditions

\begin{tabular}{||l|l|c||}
\hline \multicolumn{1}{|c||}{ Sample information } & Stressed condition & Observation \\
\hline Pure cuprizone & Vacuum at $50^{\circ} \mathrm{C}$ for 24 hours & Stable with negligible degradation \\
\hline Pure cuprizone $+18 \%$ water & Vacuum at $50^{\circ} \mathrm{C}$ for 24 hours & Stable with negligible degradation \\
\hline
\end{tabular}




\begin{tabular}{|c|c|c|}
\hline $\begin{array}{l}0.3 \% \text { cuprizone }+ \text { chow placebo }+ \\
18 \% \text { water }\end{array}$ & $\begin{array}{l}\text { Stored at room temperature for } \\
24 \text { hours followed by vacuum at } \\
50^{\circ} \mathrm{C} \text { for } 6 \text { hours (standard) or }\end{array}$ & $\begin{array}{l}10 \% \text { degradations were observed } \\
\text { in all samples regardless of drying } \\
\text { conditions }\end{array}$ \\
\hline $\begin{array}{l}0.3 \% \text { cuprizone }+ \text { chow placebo }+ \\
30 \% \text { water }\end{array}$ & 24 hours (stressed) & $\begin{array}{l}40 \% \text { degradation were observed } \\
\text { in all samples regardless of drying } \\
\text { duration }\end{array}$ \\
\hline $\begin{array}{l}0.3 \% \text { cuprizone }+ \text { chow placebo }+ \\
50 \% \text { water }\end{array}$ & & $\begin{array}{l}60 \% \text { degradation were observed } \\
\text { in all samples regardless of drying } \\
\text { duration }\end{array}$ \\
\hline
\end{tabular}

272 As shown in Table 10, when mixed only with water, cuprizone was stable even subject to high 273 drying temperature of $50{ }^{\circ} \mathrm{C}$ for 24 hours. On the contrary, when mixed with both chow and water, 274 significant degradation of cuprizone was observed. The drying duration seemed to have no impact 275 on the degree of degradation. In addition, higher water content resulted in more degradation. 276 Therefore, it appears that cuprizone can react with components in chow in the presence of water. 277 This might partially account for the low cuprizone content observed in batch B.

\section{4. CONCLUSIONS}

279 In this study, a novel, sensitive, and selective HILIC method for the determination of cuprizone has 280 been developed. The method was validated according to ICH Q2(R1). No placebo matrix component 281 was found to interfere the cuprizone determination. Good linearity and sensitivity were obtained as 282 well. The method was successfully applied to the determination of low level of cuprizone in chow. 283 In addition, it was found that cuprizone could reach with other components in chow in the presence 284 of water, which might partially account for the observed chow batch-to-batch variability in 285 cuprizone content.

\section{Conflict of interest}

288 The authors declare no conflict of interest.

\section{Acknowledgements}

291 We thank Dr. Erica Koval and Dr. Yea Jin Kaeser-Woo for their contribution and assistance to this 292 work.

\section{References}


1. L. Messori, A. Casini, C. Gabbiani, L. Sorace, M. Muniz-Miranda, and P. Zatta. Unravelling the chemical nature of copper cuprizone. Dalton Trans:2112-2114 (2007).

2. M. Kipp, T. Clarner, J. Dang, S. Copray, and C. Beyer. The cuprizone animal model: new insights into an old story. Acta Neuropathol. 118:723-736 (2009).

3. T. Skripuletz, M. Lindner, A. Kotsiari, N. Garde, J. Fokuhl, F. Linsmeier, C. Trebst, and M. Stangel. Cortical demyelination is prominent in the murine cuprizone model and is straindependent. Am J Pathol. 172:1053-1061 (2008).

4. G.K. Matsushimaand P. Morell. The neurotoxicant, cuprizone, as a model to study demyelination and remyelination in the central nervous system. Brain Pathol. 11:107-116 (2001).

5. Y. Hirahara, K.I. Matsuda, H. Yamada, A. Saitou, S. Morisaki, K. Takanami, J.M. Boggs, and M. Kawata. G protein-coupled receptor 30 contributes to improved remyelination after cuprizone-induced demyelination. Glia. 61:420-431 (2013).

6. W.W. Carlton. Studies on the induction of hydrocephalus and spongy degeneration by cuprizone feeding and attempts to antidote the toxicity. Life Sci. 6:11-19 (1967).

7. S.K. Ludwin. Central nervous system demyelination and remyelination in the mouse. An ultrastructural study of cuprizone toxicity. Lab Invest. 39:597-612 (1978).

8. W. Zhen, A. Liu, J. Lu, W. Zhang, D. Tattersall, and J. Wang. An Alternative CuprizoneInduced Demyelination and Remyelination Mouse Model. ASN Neuro. 9:1759091417725174/1759091417725171-1759091417725174/1759091417725174 (2017).

9. M.F. Stidworthy, S. Genoud, U. Suter, N. Mantei, and R.J.M. Franklin. Quantifying the early stages of remyelination following cuprizone-induced demyelination. Brain Pathol. 13:329339 (2003).

10. Q. Liu, W. Zhang, H. Wang, Y. Li, W. Liu, Q. Wang, D. Liu, N. Chen, and W. Jiang. Validation of a HILIC method for the analysis of ergothioneine in fermentation broth. J Chromatogr Sci. 54:934-938 (2016).

11. S. Ivanova, L. Peikova, P. Koleva, D. Tsvetkova, and V. Petkova. Applying HPLC - HILIC as method for analysis of pharmaceutical compounds. World J Pharm Pharm Sci. 5:01-12 (2016).

12. Q. Chen, D. Zielinski, and S.A. Nowak. Fast and sensitive method for the determination of trace 1,2,4-triazole and 4-amino-1,2,4-triazole by hydrophilic interaction liquid chromatography (HILIC) in antifungal drug substance. J Liq Chromatogr Relat Technol. 41:770-779 (2018).

13. R. Zuo, S. Zhou, Y. Zuo, and Y. Deng. Determination of creatinine, uric and ascorbic acid in bovine milk and orange juice by hydrophilic interaction HPLC. Food Chem. 182:242-245 (2015).

14. Y. Zuo, S. Zhou, R. Zuo, T. Shi, Y. Yang, and P. Henegan. Hydrophilic interaction liquid chromatography: fundamentals and applications, Nova Science Publishers, Inc.2014, pp. 121. 


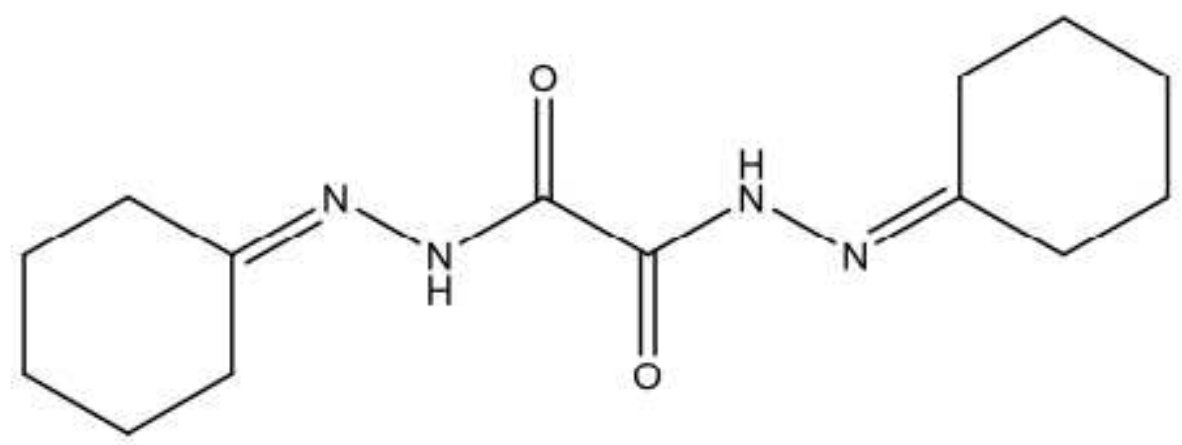

$\mathrm{N}, \mathrm{N}^{\prime}$ - bis(cyclohexylideneamino)ethanediamide

Figure 1

Chemical structure of cuprizone
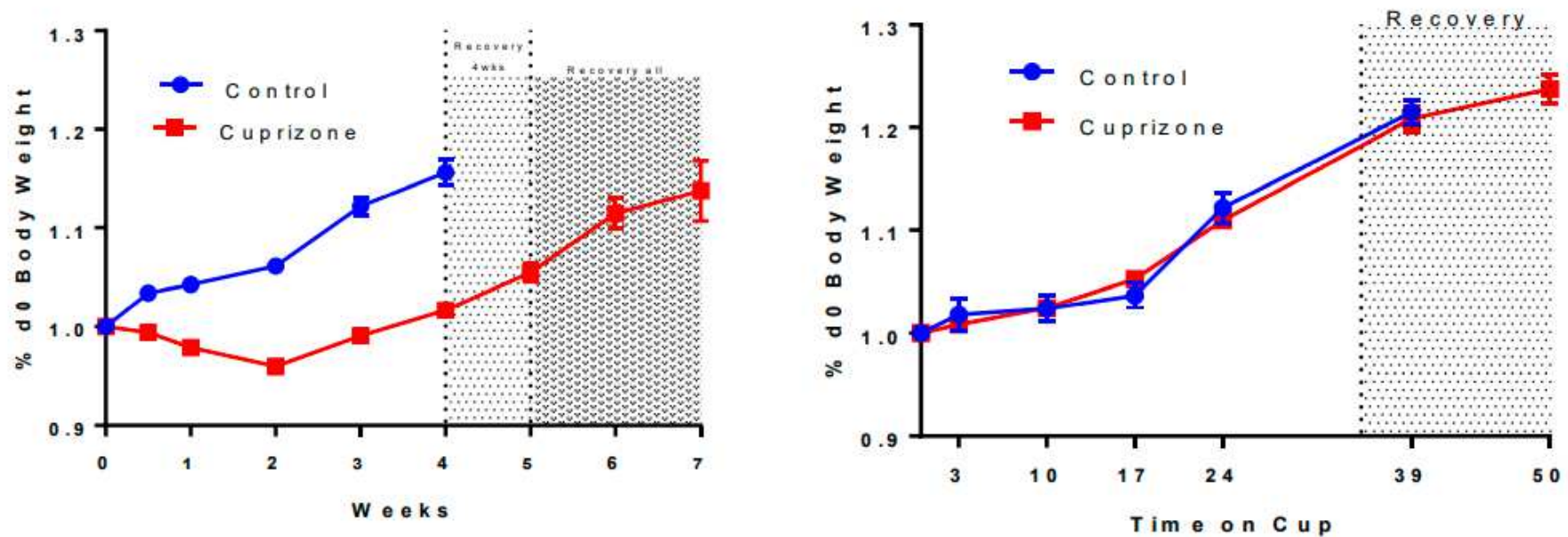

Figure 2

Weight loss of the mice were treated with chow placebo (control) and $0.3 \%$ cuprizone containing chow (batch A), $0.3 \%$ cuprizone-containing chow (batch B) 


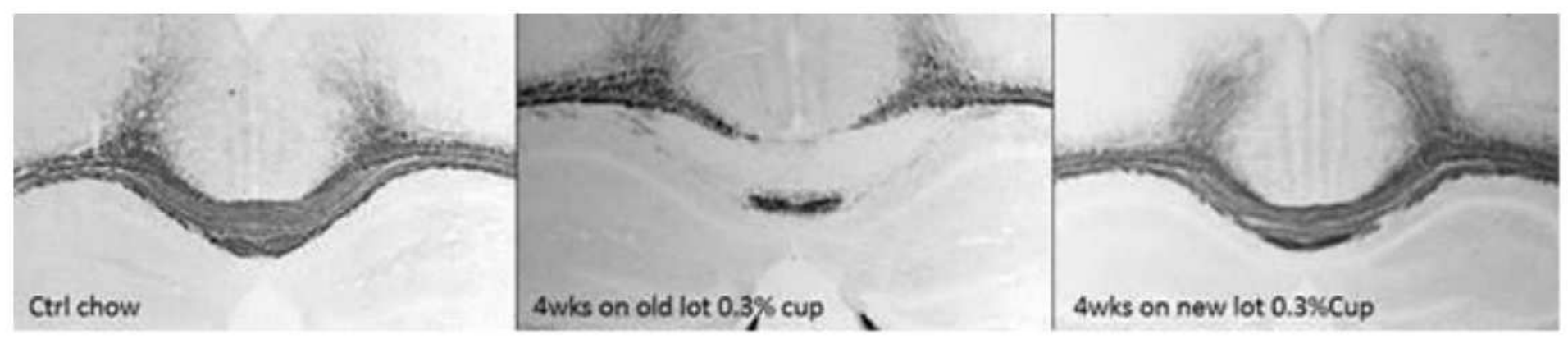

\section{Figure 3}

Demyelination detected in corpus callosum by black gold staining: The mouse on the left is on control chow, the middle mouse shows great demyelination of the corpus callosum using the batch A chow, and the mouse on the right was from the mouse using the batch B chow.
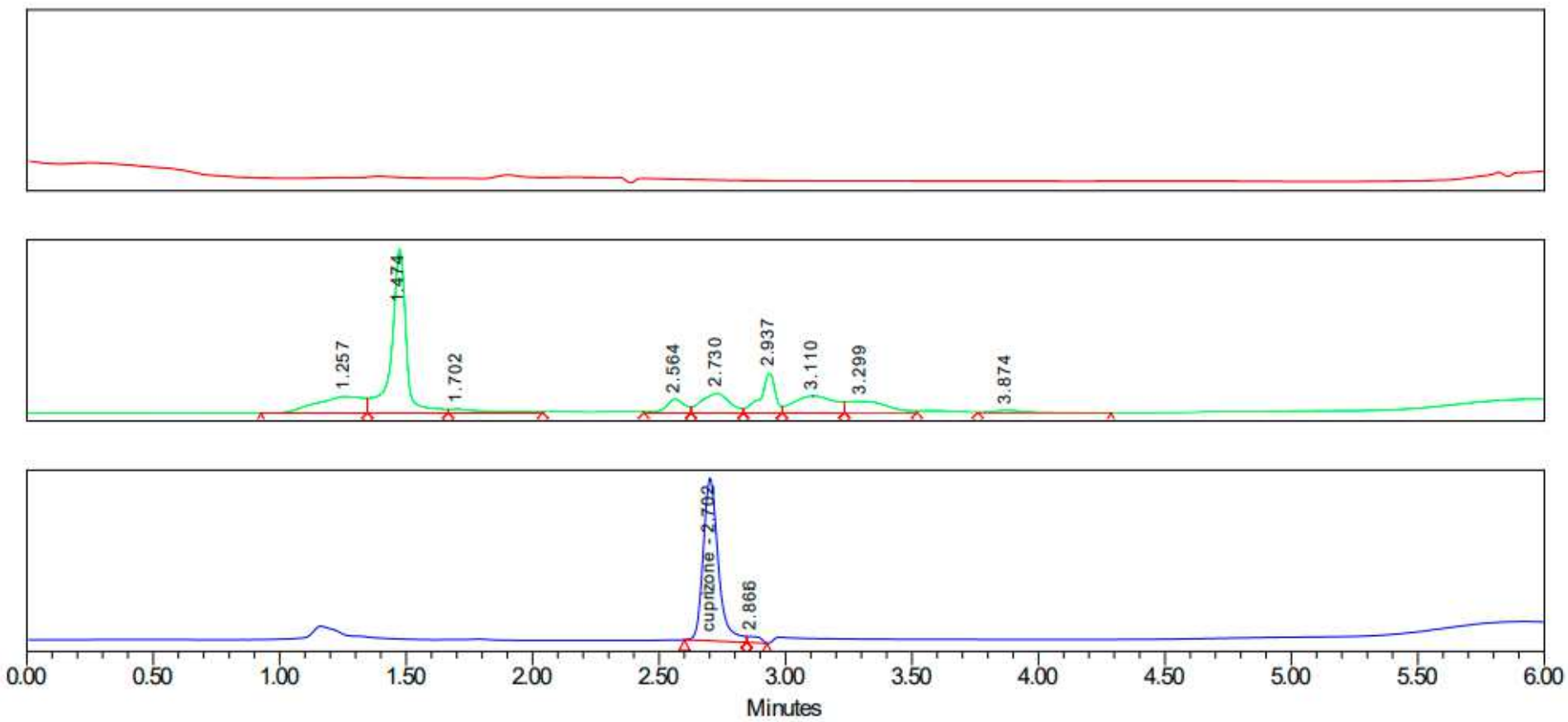

\section{Figure 4}

HPLC chromatograms of Cuprizone samples separated with Altantis T3 column; top) 1sample solvent (1:1 MeCN: water); middle) Chow placebo blank; bottom) $100 \mu \mathrm{g} / \mathrm{mL}$ cuprizone reference standard 

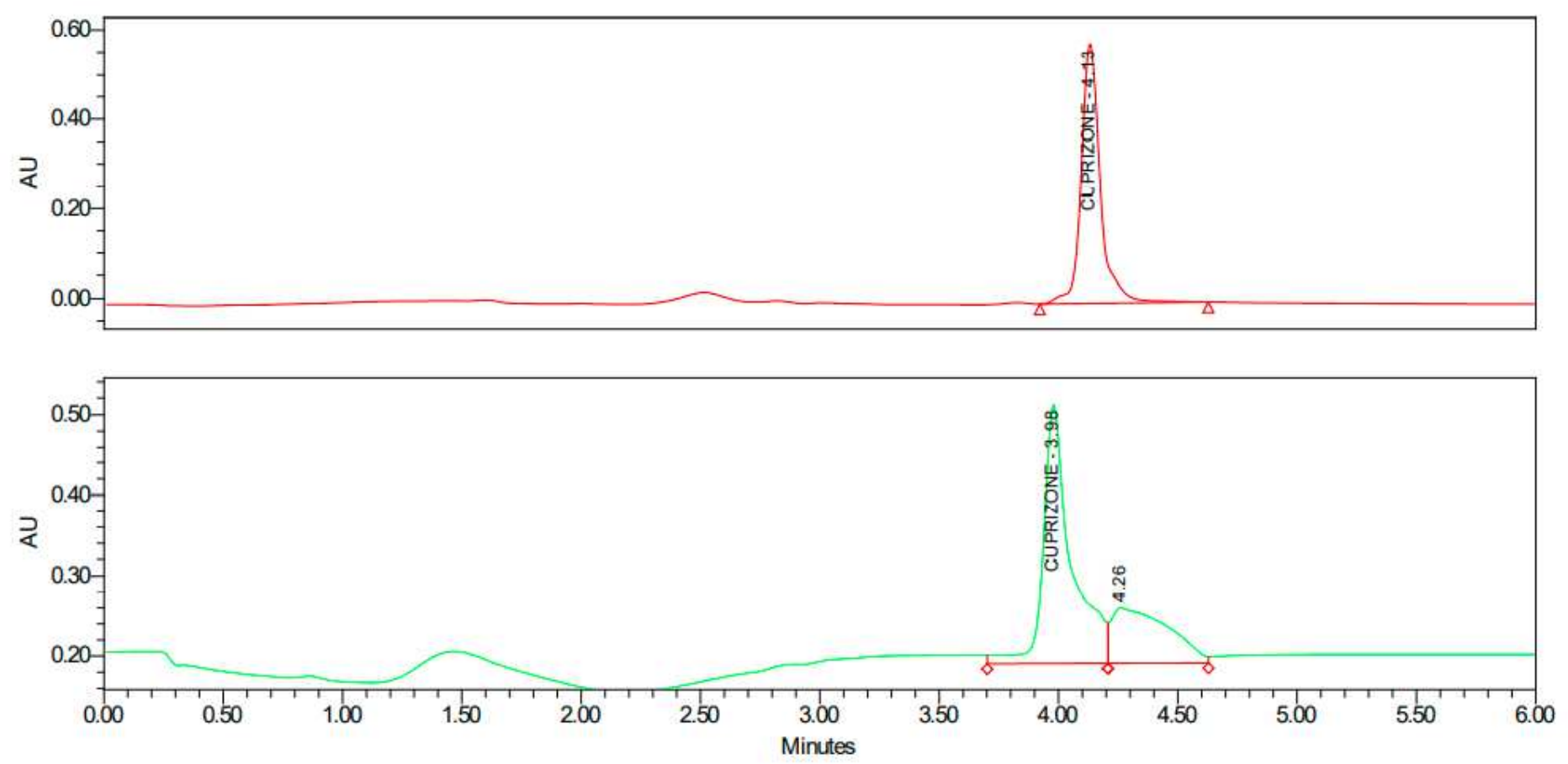

Figure 5

HPLC chromatograms for cuprizone reference standards, Xbridge HILIC column, top) 1:1 MeCN: water as sample solvent; bottom) 1:1 MeOH: water as sample solvent
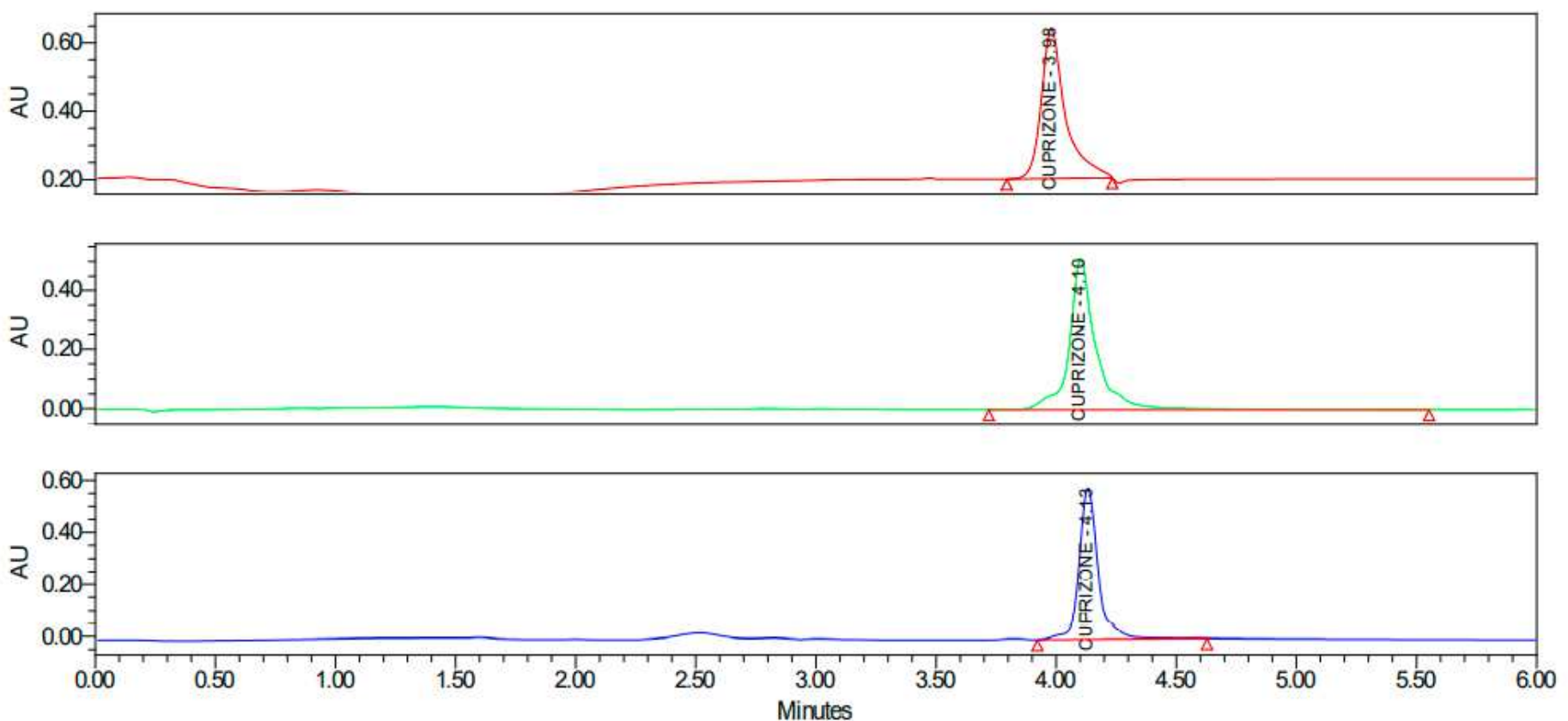

\section{Figure 6}

HPLC chromatogram of Cuprizone in Xbridge HILIC column with different mobile phases (from top to bottom): water/ MeCN; 25 mM phosphate in water/ MeCN and 0.1\%TFA in water/ MeCN 

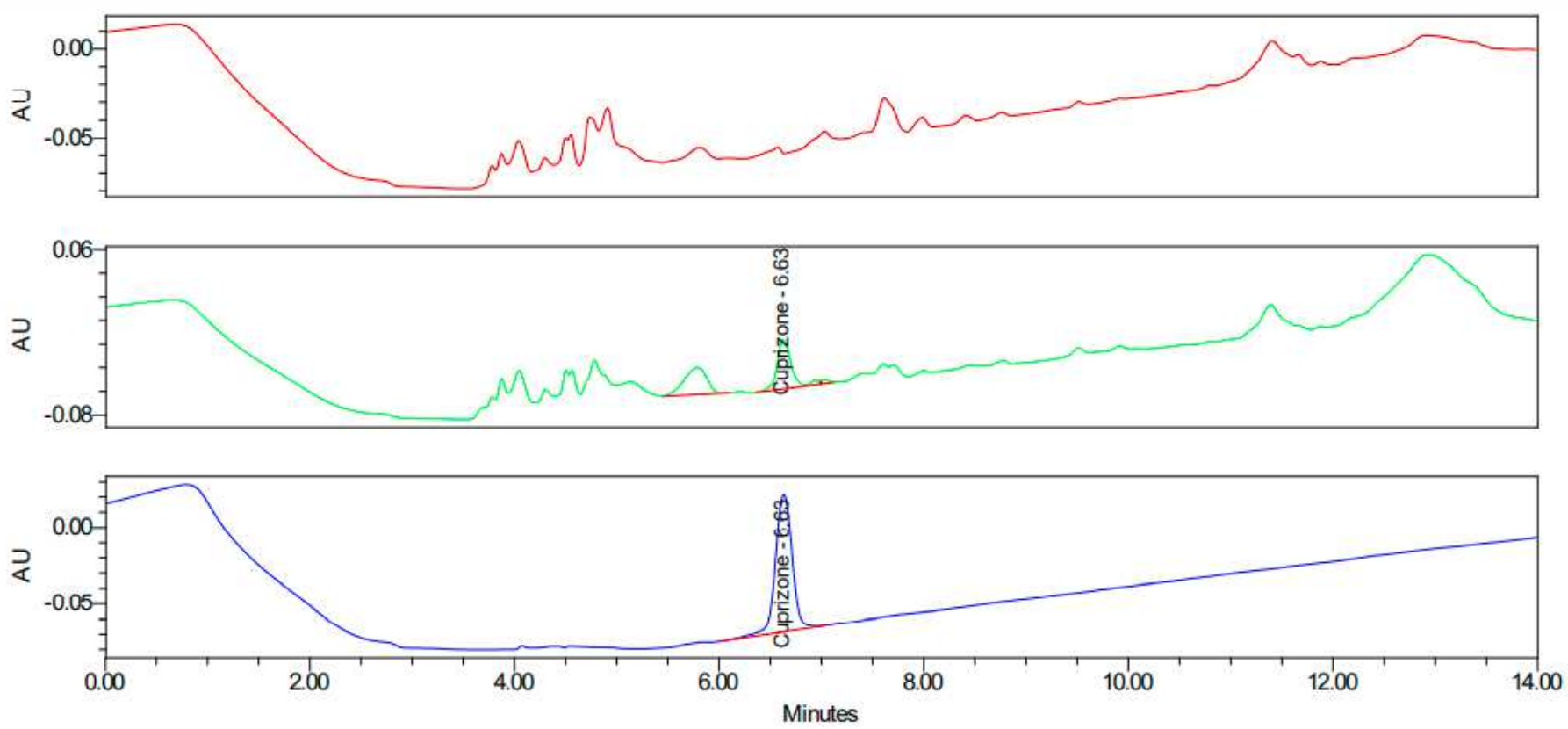

SampleName: Chow placebo

SampleName: sample B

SampleName: cuprizone std1

\section{Figure 7}

HPLC chromatogram of Cuprizone samples in Xbridge HILIC column, from top to bottom: Chow placebo blank, cuprizone-based chow sample and $100 \mu \mathrm{g} / \mathrm{mL}$ cuprizone reference standard.

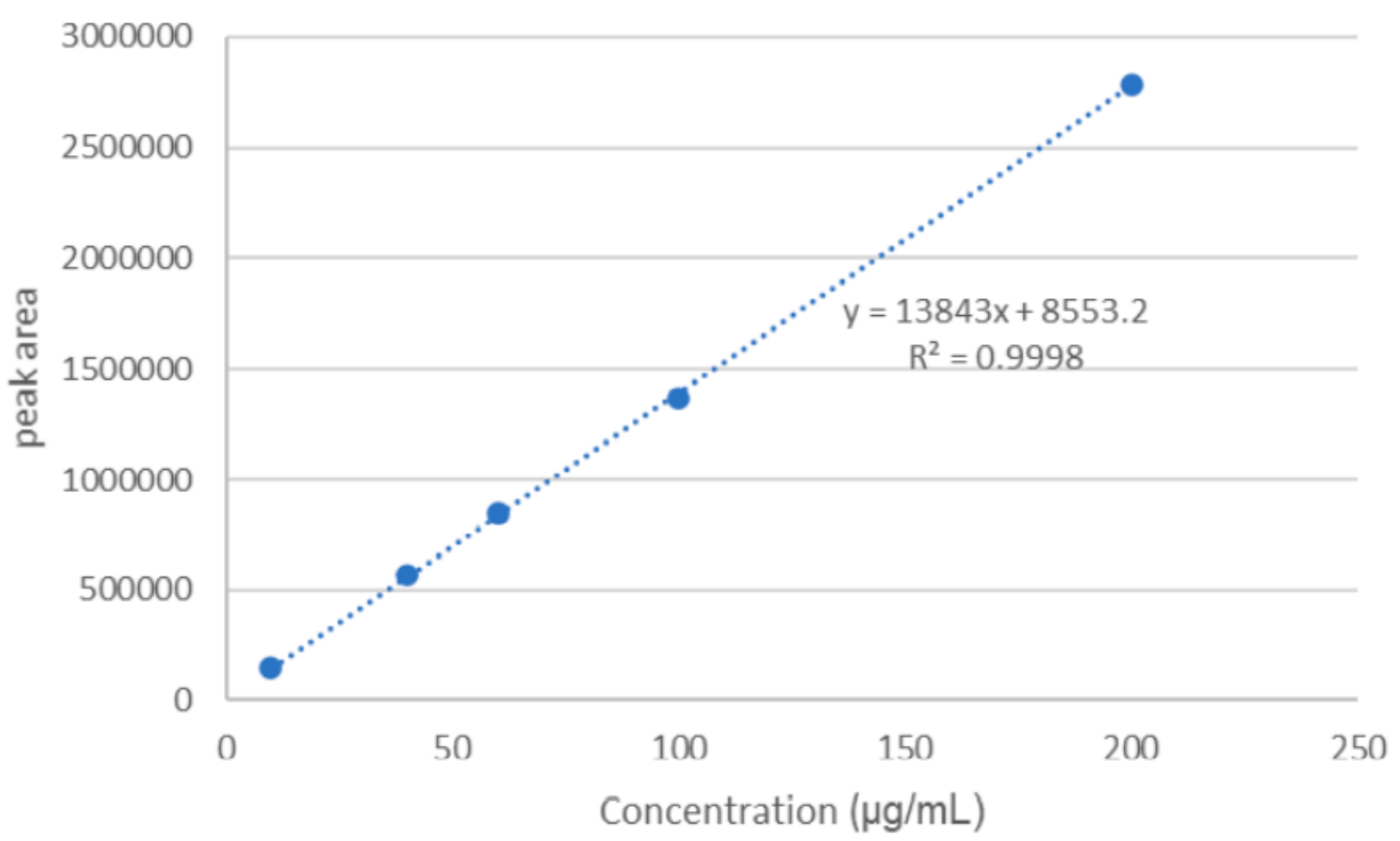


Figure 8

Calibration curve for cuprizone solutions

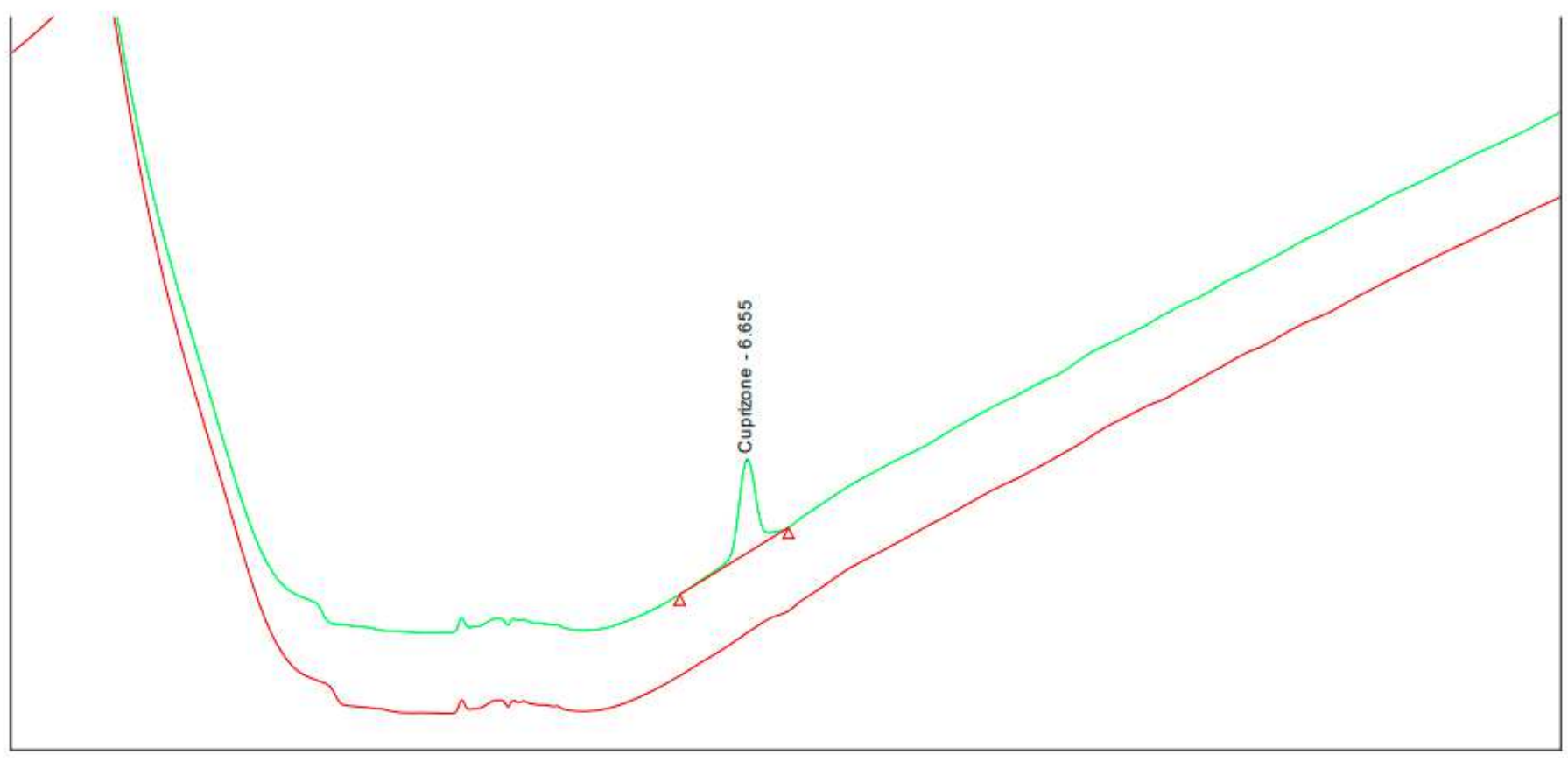

Figure 9

Chromatogram of LOQ reference standard $(2.5 \mu \mathrm{g} / \mathrm{mL}$, top) and sample solvent (1:1 MeCN: water, bottom) 